\title{
Geração fotovoltaica distribuída: importância dos agentes reguladores na expansão da geração distribuída no Nordeste
}

\section{Distributed Photovoltaic Generation: Importance of Regulatory Agents inthe Expansion of Distributed Generation in the Northeast}

Generación Fotovoltaica Repartida: Importancia de los Agentes Reguladores en la Expansión de la Generación Repartida en el Nordeste

Robson da Silva Dias (OrclD) rdrobsondias@gmail. com Universidade Federal do Ceará (UFC)

\section{Production photovoltaïque distribuée: L'Importance des Agents de Réglement dans l'Expansion de la Production Distribuée dans le Nord-Est du Brésil}

\section{Resumo}

No presente artigo, é analisada a importância dos agentes reguladores do setor elétrico brasileiro com a finalidade de alavancar a geração distribuída (GD) no Nordeste, particularmente nos estados da Bahia, Ceará, Pernambuco, Rio Grande do Norte e Piauí. O principal objetivo é verificar o atual cenário de GD nesses estados e como medidas regulatórias impactam na curva de expansão da potência instalada. Outro fator impulsionador analisado é a aprovação do financiamento para pessoas físicas por parte do Banco Nacional de Desenvolvimento Econômico e Social (BNDES), no início de junho de 2018. Esse financiamento pode facilitar o acesso à aquisição de sistemas fotovoltaicos (FV) para as pessoas físicas e alavancar ainda mais a GD. Também é apresentada uma previsão de potência instalada no Brasil até 2021, visando dimensionar o potencial energético desse tipo de geração.

Palavras-chave: Geração Distribuída. Agentes regulatórios e sistemas fotovoltaicos.

\begin{abstract}
This paper analyzes the importance of regulators in the Brazilian electricity sector in order to promote Distributed Generation in the Northeast, particularly in the states of Bahia, Ceará, Pernambuco, Rio Grande do Norte and Piauí. The main objective is to verify the current scenario of distributed generation in these states and how regulatory impact on the installed power expansion curve measures. Another driving factor analyzed is the approval of financing for individuals by the Banco Nacional de Desenvolvimento Econômico e Social (BNDES) in early June 2018. This financing can facilitate access to the acquisition of photovoltaic systems for individuals and leverage, even more, the Distributed Generation. It is also made a forecast of power installed in Brazil until 2021, aiming at sizing the energy potential of this type of generation.
\end{abstract}

Keywords: Distributed Generation. Regulatory gents and photovoltaic systems.

\section{Resumen}

Este artículo analiza la importancia de los agentes reguladores del sector eléctrico brasileño con el objetivo de apalancar la Generación Repartida (GR) en el Nordeste, particularmente 
en los Estados de Bahía, Ceará, Pernambuco, Rio Grande do Norte y Piauí. El objetivo principal es verificar el actual escenario de GR en estos Estados y cómo medidas reguladoras impactan en la curva de expansión de la potencia instalada. Otro factor impulsor analizado fue la aprobación del financiamiento para personas físicas por parte del Banco Nacional de Desarrollo Económico y Social (BNDES), al inicio de junio de 2018. Este financiamiento puede facilitar el acceso a la adquisición de sistemas fotovoltaicos (FV) para personas físicas Y apalancar aún más la GR. También es presentada una previsión de potencia instalada en Brasil hasta 2021, objetivando dimensionar el potencial energético de este tipo de generación.

Palabras-clave: Generación Repartida. Agentes reguladores y sistemas fotovoltaicos.

\section{Résumé}

Cet article analyse l'importance des agents de réglement du secteur électricité au Brésil pour dynamiser de la Production distribuée dans le Nord-Est du Brésil, en particulier dans les États de Bahia, Ceará, Pernambuco, Rio Grande do Norte et Piauí. L'objectif principal est de vérifier le scénario de la Production Distribuée actuel dans ces États et aussi d'évaluer l'impact des mesures réglementaires sur la courbe d'expansion de la puissance installée. D'autre facteur déterminant analysé est l'approbation du financement pour des personnes physiques par la Banque Nationale de Développement Economique et Social (BNDES) au début du mois de juin 2018. Ce financement peut faciliter l'accès des personnes physiques à l'acquisition de systèmes photovoltaïques $(\mathrm{PV})$ et dynamiser encore plus la technologie de la Production Distribuée Il est également présenté une prévision de puissance installée au Brésil jusqu'en 2021, ce qui vise à dimensionner le potentiel énergétique de ce type de production.

Mots-clés:Production distribuée. Agents de réglement et systèmes photovoltaïques.

\section{Introdução}

A geração distribuída (GD) é definida como uma fonte de energia elétrica conectada diretamente à rede de distribuição ou situada no próprio consumidor. No Brasil, a definição de GD é feita a partir do artigo $14^{\circ}$ do Decreto Lei n. ${ }^{\circ}$ 5.163/2004, atualizada pelo Decreto n. ${ }^{\circ}$ 786/2017.

Considera-se GD toda produção de energia elétrica proveniente de agentes concessionários, permissionários ou autorizados conectados diretamente ao sistema elétrico de distribuição, exceto aquela proveniente de: hidrelétrica com capacidade instalada superior a $30 \mathrm{MW}$, termelétrica, inclusive de cogeração, com eficiência energética inferior a 75\% (CADERNO DE RECURSOS ENERGÉTICOS DISTRIBUÍDOS - FGV ENERGIA, s.d. apud PEREIRA, 2019).

Os principais benefícios agregados à GD são:

- Diversificação da matriz energética, reduzindo cada vez mais a dependência pela geração hidrelétrica;

- Redução de perdas por transmissão de energia, considerando que a GD é disponibilizada próxima ao consumo;

- Possibilidade de desenvolver em cadeia produtiva nacional;

- Equilíbrio de cargas no sistema na rede de distribuição e na fronteira com a rede básica;

- Matriz energética mais sustentável;

- Melhor aproveitamento dos recursos;

- Maior eficiência energética nos empreendimentos.

O Brasil tem um grande valor de irradiação solar anual (1.550 a $2.350 \mathrm{kWh} / \mathrm{m}^{2}$, segundo o Portal Solar), com uma baixa variabilidade sazonal e interanual devido à localização em uma região tropical. Adicionalmente, hidroelétricas brasileiras possuem regimes sazonais quase similares, com grandes vazões ocorrendo de dezembro a abril, que é considerada a estação chuvosa, e baixos níveis de reservatórios de julho a outubro, considerado o período seco. O recurso solar é complementar ao regime hídrico sazonal, com os mais baixos 
níveis de irradiação ocorrendo durante os meses chuvosos, devido ao maior nível de cobertura de nuvens. Assim, plantas solares conectadas à rede podem economizar água dos reservatórios durante os críticos meses secos.

A Figura 1 apresenta a potência instalada de GD por fonte no país para o mês de outubro de 2018. A participação da potência instalada FV representa $81 \%$ da potência total gerada, sinalizando uma predominância dessa tecnologia no ambiente de GD no Brasil. Na interligação com a rede elétrica em GD, plantas FV são encontradas, principalmente, integradas às edificações, em ambientes urbanos, exigindo o uso de circuitos eletrônicos, com as tarefas de proteção do sistema, operação no ponto de potência máxima, conversão da corrente contínua em alternada e limitação do conteúdo de harmônicos (BORGES NETO; CARVALHO, 2012)

Figura 1: Participação da potência instalada da GD por fonte, outubro 2018, Brasil.

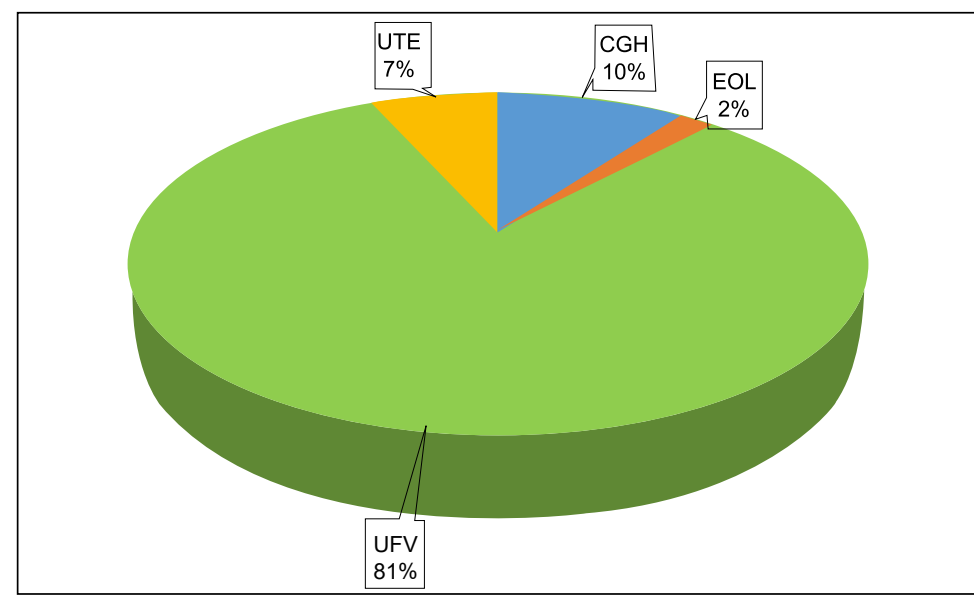

Fonte: ANEEL (2018).

Legenda: UFV: Central Fotovoltaica; EOL: Eólica, CGH: Central Geradora Hidráulica e UTE: Unidades Termelétricas.

A Figura 2 detalha por classe de consumo a quantidade de instalações de GD no Brasil em outubro de 2018. Observa-se uma predominância da classe residencial, com 32.698 clientes de um total de 43.160, ou seja, $75,8 \%$ de participação.

Figura 2: Número de clientes GD por classe de consumo, outubro 2018, Brasil.

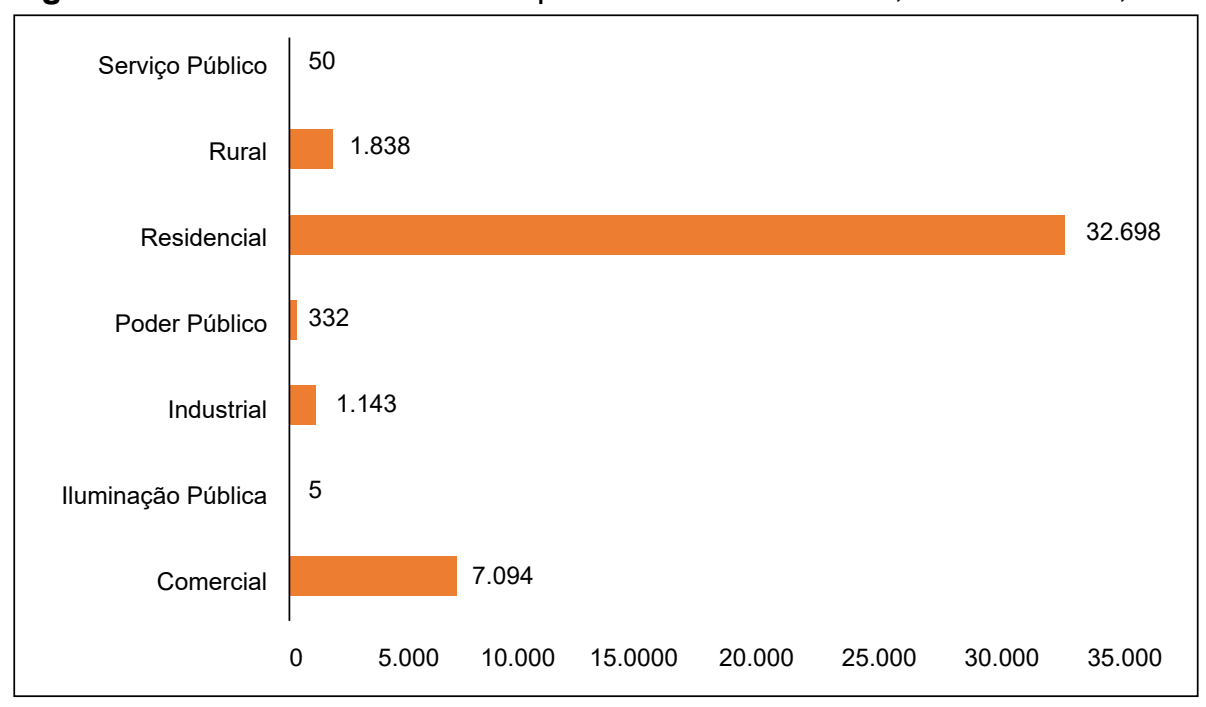

Fonte: ANEEL (2018). 
A Figura 3 apresenta a distribuição de clientes GD por estados brasileiros. Minas Gerais é o estado com mais unidades de GD (8.226), seguido por São Paulo (8.072) e Rio Grande do Sul (5.381). O estado do Ceará possui 1.293 unidades de GD. Como esperado, estados das Regiões Sudeste e Sul, por terem uma maior renda per capita, têm liderança de GD no país.

Figura 3: Clientes GD por estado, outubro 2018, Brasil.

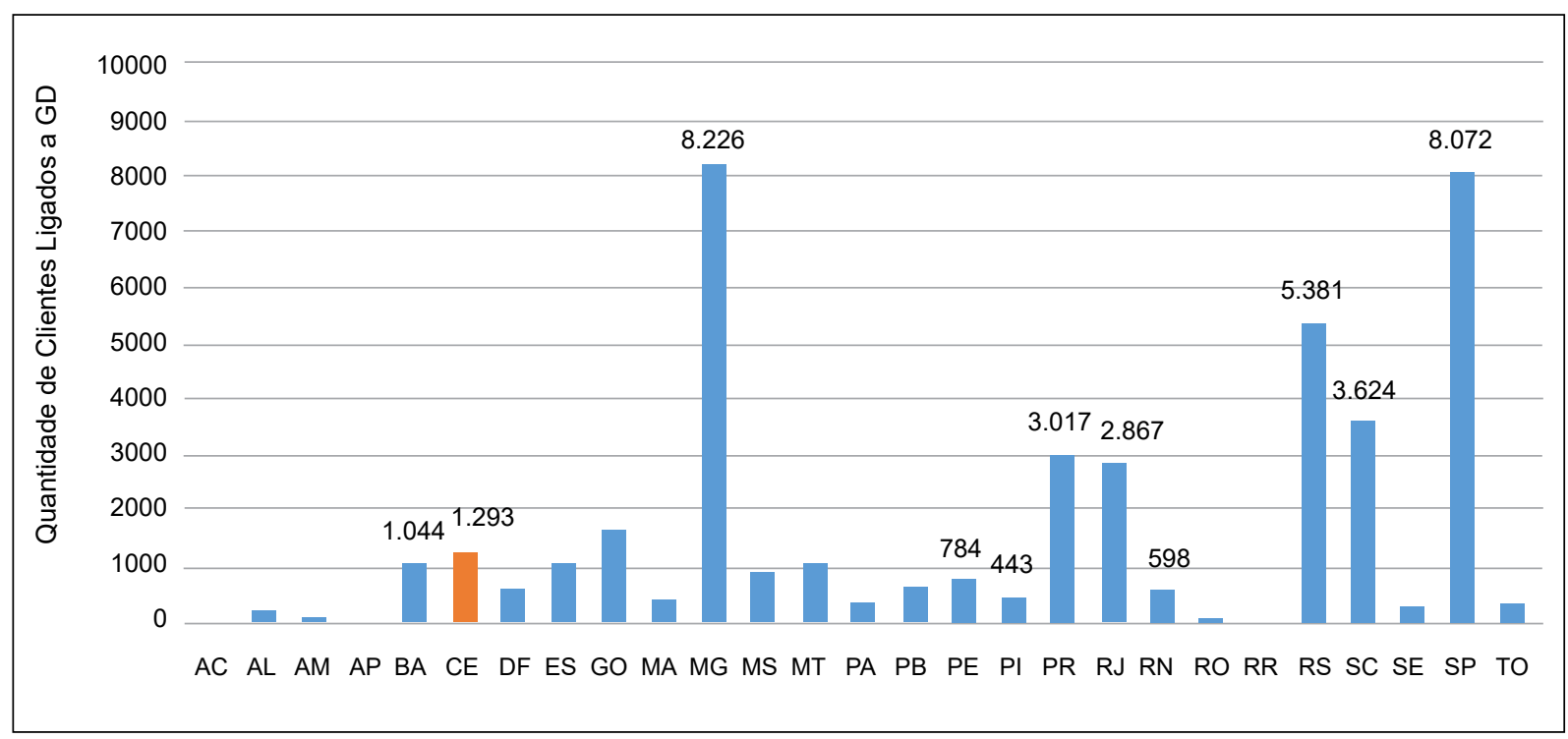

Fonte: ANEEL (2018).

A Tabela 1 apresenta a evolução da capacidade instalada de GD (2014 - 2017) quando comparada com a capacidade de geração elétrica no Brasil. Apesar de ainda representar uma participação relativamente baixa (menos de 1\%), já se nota uma evolução de um ano para o outro, ou seja, tem-se um potencial de avanço significativo para os próximos anos caso a GD continue a crescer nos patamares dos últimos anos.

Tabela 1 - Capacidade instalada de geração elétrica e GD no Brasil (MW) entre 2014 e 2017.

\begin{tabular}{l|c|c|c|c}
\hline Capacidade instalada de geração elétrica (MW) & $\mathbf{2 0 1 4}$ & $\mathbf{2 0 1 5}$ & $\mathbf{2 0 1 6}$ & $\mathbf{2 0 1 7}$ \\
\hline Brasil & 133.913 & 140.858 & 150.338 & 157.112 \\
\hline GD & 3 & 15 & 83 & 256 \\
\hline \% GD/Brasil & $0,00 \%$ & $0,01 \%$ & $0,06 \%$ & $0,16 \%$ \\
\hline
\end{tabular}

Fonte: Elaborada pelo autor como nos dados da EPE (2014 a 2017).

\section{Legislação governamental brasileira sobre a GD}

A regulação adaptou-se às características particulares da GD. Por exemplo, o Decreto n. ${ }^{\circ}$ 5.163/2004 (que criou a figura do gerador distribuído), estabeleceu um ambiente de contratação diferente: a possibilidade da geração distribuída "vender" energia a empresas de distribuição, ao invés de vender em leilões, através de chamada pública organizada pela empresa de distribuição.

Em abril de 2012, a ANEEL introduziu o mecanismo de GD através da Resolução Normativa n. ${ }^{\circ} 482$, a fim de reduzir as barreiras à conexão de pequenas usinas de fontes renováveis para redes de distribuição, no qual um consumidor, devidamente conectado a uma rede de distribuição, pode injetar na rede a energia excedente para uso posterior. 
Além disso, a Resolução $n .^{\circ} 482$ definiu os procedimentos para acesso à rede de distribuição. Um dos principais aspectos do acesso à rede de distribuição é para definir quem deve arcar com os custos adicionais associados à conexão da geração distribuída. Para facilitar sua inserção, essa resolução definiu que a distribuidora será responsável pela análise de impacto e por parte dos custos associados (a distribuidora assume o custo referente ao sistema de medição convencional, já o cliente assume o custo complementar referente ao custo dos componentes do sistema de medição bidirecional requeridos para o sistema de compensação de energia elétrica).

Em abril de 2015, três anos após essa resolução normativa, existiam apenas 478 sistemas FV instalados no Brasil, o que ocasionou uma atualização desse regulamento em novembro de 2015 (ANEEL, 2015), abordando os limites da capacidade instalada e regimes de compensação.

O normativo define microgeração como uma usina com capacidade instalada menor ou igual a $75 \mathrm{~kW}$ e minigeração como uma unidade com potência instalada maior que $75 \mathrm{~kW}$ e menor ou igual a $5 \mathrm{MW}$. Além disso, essa resolução define um regime de compensação, concedendo um crédito a consumidores que podem ser usados por até 60 meses se a quantidade de energia injetada na rede for maior que a consumida.

A Resolução Normativa n. ${ }^{\circ} 414$ introduz o conceito de custo da disponibilidade (ANEEL, 2010), que expressa o valor pago pelos consumidores residenciais para garantir a disponibilidade de fornecimento de energia elétrica. Essa compensação financeira varia de acordo com a conexão à rede: para conexões de rede monofásicas, esse custo equivale ao consumo de $30 \mathrm{kWh}$; para conexões de duas fases, é equivalente a 50 kWh; para conexões trifásicas, é equivalente a $100 \mathrm{kWh}$ (ANEEL, 2010).

Essa resolução tem um impacto importante no fluxo de caixa do sistema FV, bem como em seu dimensionamento. Tendo em mente que o consumidor deve pagar o custo da disponibilidade de eletricidade todos os meses, o sistema FV não deve ser dimensionado para suprir toda a demanda residencial mensal, mas, sim, levando em consideração a demanda descontada equivalente ao custo de disponibilidade de eletricidade.

Em abril de 2015, o Conselho Nacional de Política Financeira (CONFAZ) publicou o Convênio ICMS 16/2015 que determina:

Cláusula primeira Ficam os estados do Acre, Alagoas, Amapá, Amazonas, Bahia, Ceará, Espírito Santo, Goiás, Maranhão, Mato Grosso, Mato Grosso do Sul, Minas Gerais, Pará, Paraíba, Paraná, Pernambuco, Piauí, Rio de Janeiro, Rio Grande do Norte, Rio Grande do Sul, Rondônia, Roraima, Santa Catarina, São Paulo, Sergipe, Tocantins e o Distrito Federal autorizados a conceder isenção do ICMS incidente sobre a energia elétrica fornecida pela distribuidora à unidade consumidora, na quantidade correspondente à soma da energia elétrica injetada na rede de distribuição pela mesma unidade consumidora com os créditos de energia ativa originados na própria unidade consumidora no mesmo mês, em meses anteriores ou em outra unidade consumidora do mesmo titular, nos termos do Sistema de Compensação de Energia Elétrica, estabelecido pela Resolução Normativa nº 482, de 17 de abril de 2012 (CONFAZ, 2015, on-line).

Em outras palavras, o convênio concede isenção de ICMS na fatura do consumidor de geração distribuída limitada à energia injetada pelo cliente. Dessa forma, o cliente pagará ICMS somente sobre o saldo de eletricidade, ou seja, a diferença entre a energia consumida e a energia injetada na rede.

Esses subsídios do governo são extremamente importantes para impulsionar a penetração de sistemas FV na rede de distribuição, o que significa que uma adequada estrutura de incentivo para esses sistemas favorecerá a sua penetração na GD no Brasil.

A partir desse incentivo governamental, verifica-se seu efeito na evolução da GD após sua vigência (22/04/15).

A Figura 4 mostra a evolução da penetração de sistemas FV entre consumidores residenciais no Brasil, através da potência instalada em kW, que quase não foi percebido pela resolução em 2012, e foi significativamente impulsionado pelo Convênio ICMS n. ${ }^{\circ}$ 16/2015. 
Figura 4: Potência instalada residencial (kW), outubro 2018, Brasil.

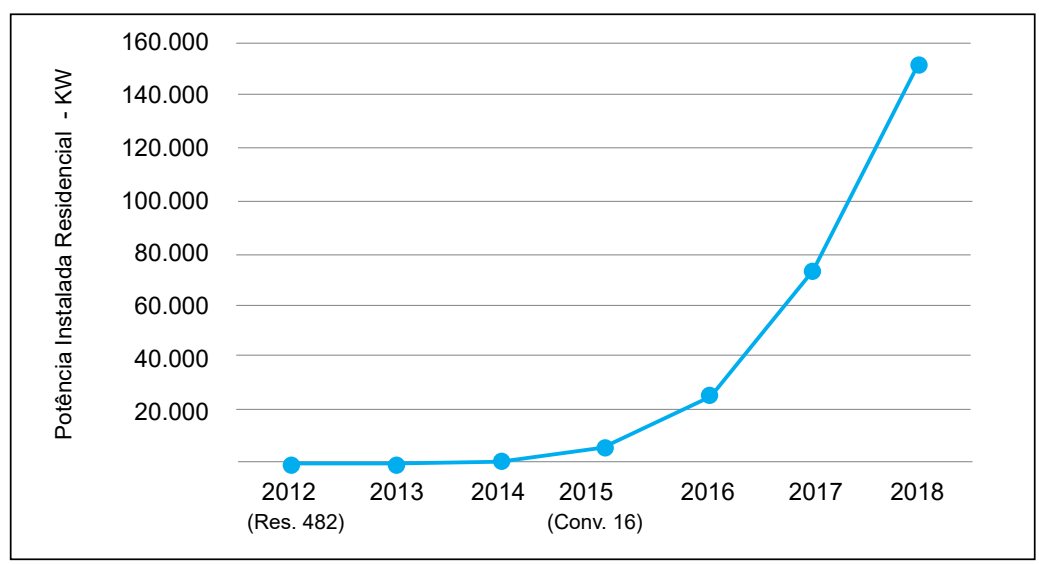

Fonte: ANEEL (2012 a 2018).

Outro incentivo importante que pode impulsionar ainda mais a GD no Brasil é a aprovação do financiamento para pessoas físicas do BNDES. Em 5 de junho de 2018, o Banco Nacional de Desenvolvimento Econômico e Social (BNDES) aprovou mudanças no Programa Fundo Clima. A partir de agora, no subprograma Máquinas e Equipamentos Eficientes, pessoas físicas terão acesso a financiamentos para a instalação de sistemas de aquecimento solar e sistemas de cogeração (placas FV, aerogeradores, geradores a biogás e equipamentos necessários), com taxas de financiamento a partir de 4,03\% a.a. Trata-se de mais uma ação do BNDES para incentivar o cidadão brasileiro a investir em sustentabilidade e economia de energia. Os recursos poderão ser contratados em operações indiretas somente por meio de bancos públicos.

O Fundo Clima é destinado a projetos de Mobilidade Urbana, Cidades Sustentáveis, Resíduos Sólidos, Energias Renováveis, Máquinas e Equipamentos Eficientes, e outras iniciativas inovadoras. O objetivo é financiar produções e aquisições com altos índices de eficiência energética ou que contribuam para redução de emissão de gases de efeito estufa.

\section{Dados de GD Brasil/Nordeste/Ceará}

\subsection{Dados de GD do Brasil}

No Brasil, nos anos de 2014 e 2015, a GD aparecia com poucos clientes. Já nos anos de 2016 e 2017, a inclinação da reta fica mais acentuada. A Fig. 5 apresenta o perfil da potência instalada de GD no Brasil de 2014 até outubro de 2018. No período de 2017 para 2018, a GD teve um crescimento na potência instalada de $107 \%$.

Figura 5: Evolução da potência instalada GD anual (kW), Brasil.

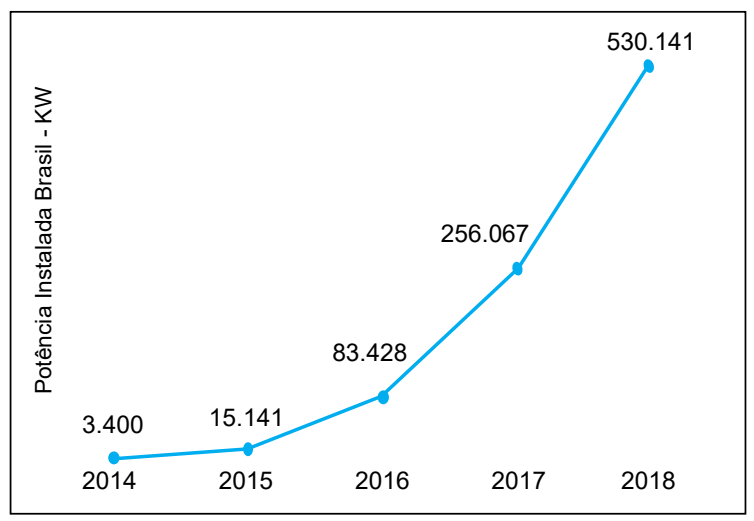

Fonte: ANEEL (2014 a 2018). 
A Figura 6 apresenta o perfil da quantidade de clientes de GD no Brasil de 2014 até outubro de 2018. No mesmo período de 2017 para 2018, a GD teve um crescimento na base de consumidores de 96\%.

Figura 6: Evolução de clientes GD, Brasil.

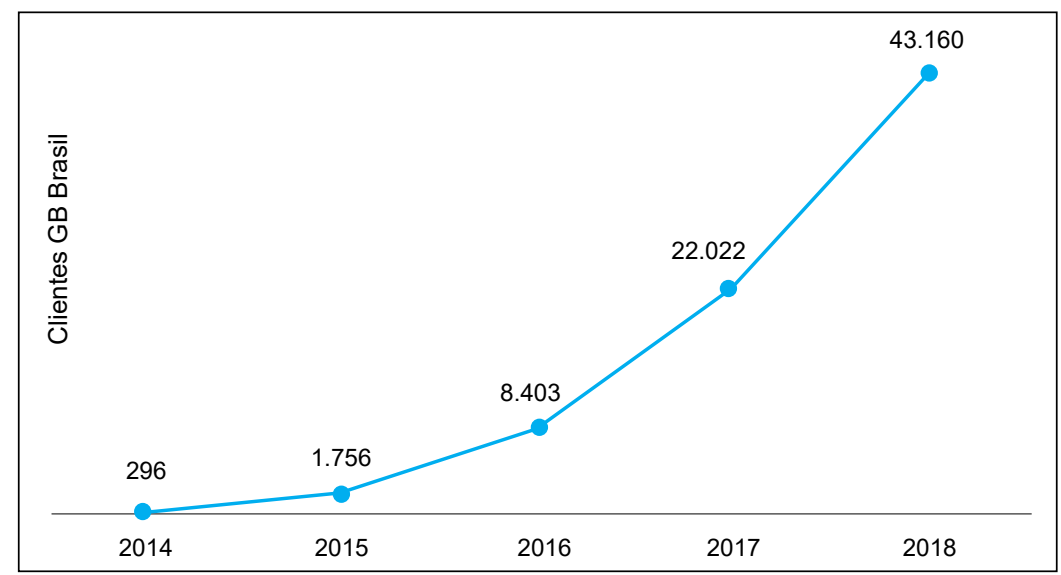

Fonte: ANEEL (2014 a 2018).

A Figura 7 mostra o crescimento anual de clientes GD no Brasil. Observa-se um expressivo crescimento em 2015, de 493\% frente a 2014, fruto do reflexo da aprovação do Convênio ICMS n. ${ }^{\circ}$ 16/2015. Nos anos seguintes, há uma desaceleração da expansão, como reflexo da crise econômica pela qual passava o país. Apesar disso, em 2018, a base de clientes está 96\% acima em relação ao ano de 2017. Destaca-se que estão computados os dados até outubro de 2018, já a comparação de 2017 é com o ano todo. Portanto, percebe-se uma desaceleração no ritmo de clientes conectados a GD pelos seguintes motivos: crise econômica nacional, base de comparação bastante elevada, assim como apuração dos dados de 2018 até outubro.

Figura 7: Crescimento anual de clientes GD, Brasil.

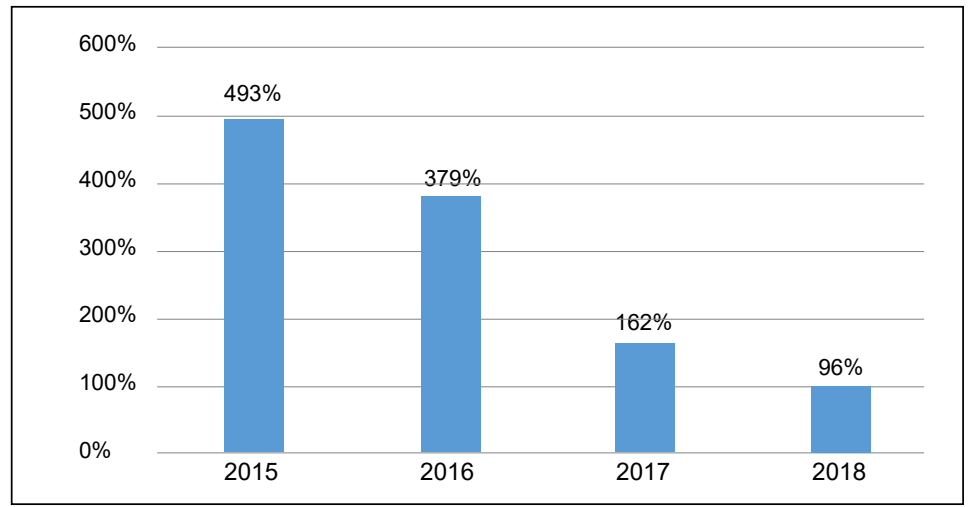

Fonte: ANEEL (2015 a 2018).

Já a Figura 8 apresenta o crescimento anual da potência instalada GD no Brasil, caracterizado por elevadas taxas de crescimento, principalmente em 2015 e 2016. Nos anos seguintes, há uma desaceleração da expansão, consequência da crise econômica nacional. Em 2018, a potência instalada estava 107\% acima em relação ao ano de 2017. Destaca-se que estão computados os dados até outubro de 2018, já a comparação de 2017 é com o ano todo. Portanto, percebe-se uma desaceleração no ritmo de crescimento da potência instalada de GD no Brasil pelos seguintes motivos: crise econômica nacional, base de comparação bastante elevada, assim como apuração dos dados de 2018 até outubro. 
Figura 8: Crescimento anual potência instalada de GD, Brasil.

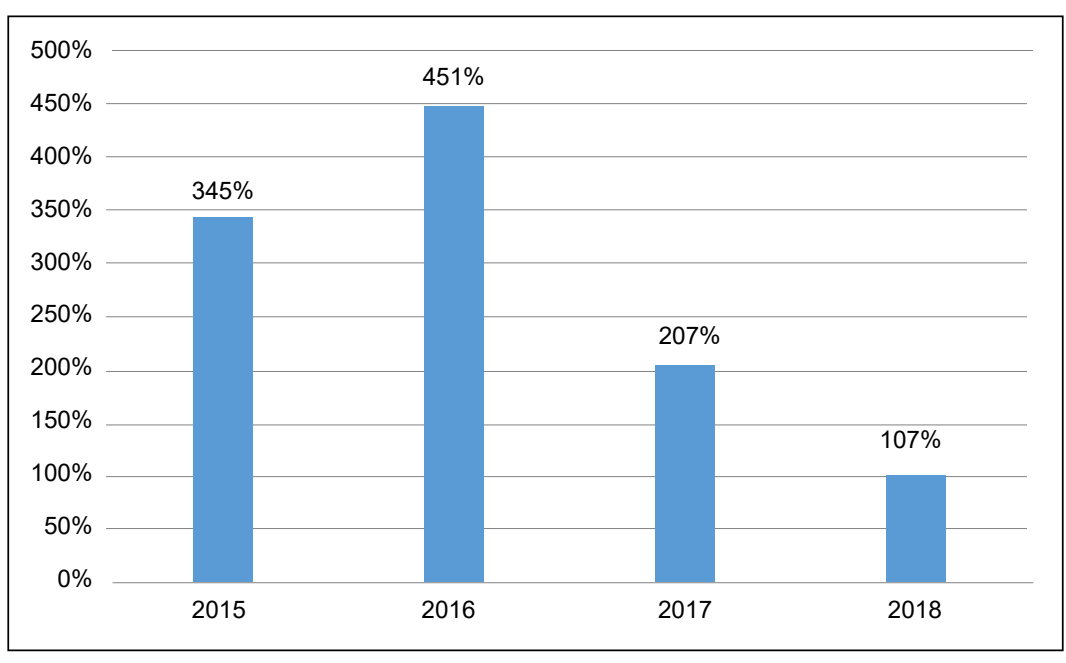

Fonte: ANEEL (2015 a 2018).

A Tabela 2 apresenta o incremento de unidades consumidoras de GD no Brasil entre os anos de 2015 e 2018. Conforme tabela, a cada ano, o acréscimo é sempre maior que o do ano anterior.

Tabela 2 - Aumento de unidades consumidoras (UC) de GD no Brasil entre 2015 e 2018 por ano.

\begin{tabular}{c|c}
\hline Período & Acréscimo de UC \\
\hline Jan 2015 - Dez 2015 & +1.460 \\
\hline $\operatorname{Jan} 2016-\operatorname{Dez} 2016$ & +6.647 \\
\hline $\operatorname{Jan} 2017-\operatorname{Dez} 2017$ & +13.619 \\
\hline $\operatorname{Jan} 2018-\operatorname{Dez} 2018$ & +21.138 \\
\hline
\end{tabular}

Fonte: Elaborada pelo autor como nos dados da ANEEL (2015 a 2018).

Conforme Tabela 2, uma aceleração do acréscimo de unidades consumidoras (UC) de GD pode ser verificada de janeiro a dezembro de 2017 quando comparado ao mesmo período de 2016. Em janeiro a outubro de 2018 também se observa esse incremento importante, chegando em out/18 com 43.160 clientes GD no Brasil.

A Tabela 3 apresenta o incremento de potência instalada de GD no Brasil entre os anos de 2015 e 2018. Conforme tabela, assim como na base de clientes, a cada ano o acréscimo é sempre maior que o do ano anterior.

Tabela 3 - Aumento de potência instalada de GD no Brasil entre 2015 e 2018 por ano.

\begin{tabular}{c|c}
\hline Período & Acréscimo de kW \\
\hline Jan 2015 - Dez 2015 & +11.741 \\
\hline Jan 2016 - Dez 2016 & +68.287 \\
\hline Jan 2017 - Dez 2017 & +172.639 \\
\hline Jan 2018 - Out 2018 & +270.074 \\
\hline
\end{tabular}

Fonte: Elaborada pelo autor utilizando dados da ANEEL (2015 a 2018).

Conforme Tabela 3, uma aceleração do acréscimo de potência instalada pode ser verificada de janeiro a dezembro de 2017 quando comparado ao mesmo período de 2016. De janeiro a outubro de 2018, também se verifica um incremento significativo, chegando em out/18 com 530,1 MW de potência instalada no Brasil. 
A Figura 9 mostra a previsão de potência instalada (kW) no Brasil de GD. Considerando as premissas de crescimento encontradas no país para a potência instalada, constrói-se um cenário para os próximos três anos. A potência instalada tem previsão de fechar 2018 com 585 MW e, em 2021, com um total de 2.031 MW. A previsão de potência instalada de 2019 a 2021 foi feita considerando os crescimentos dos últimos anos e adaptou-se à desaceleração da expansão (conforme Figura 8) no modelo de previsão. A partir de 2019, foi mantida a mesma taxa de crescimento até 2021.

Figura 9: Previsão de potência instalada (kW) de GD, Brasil.

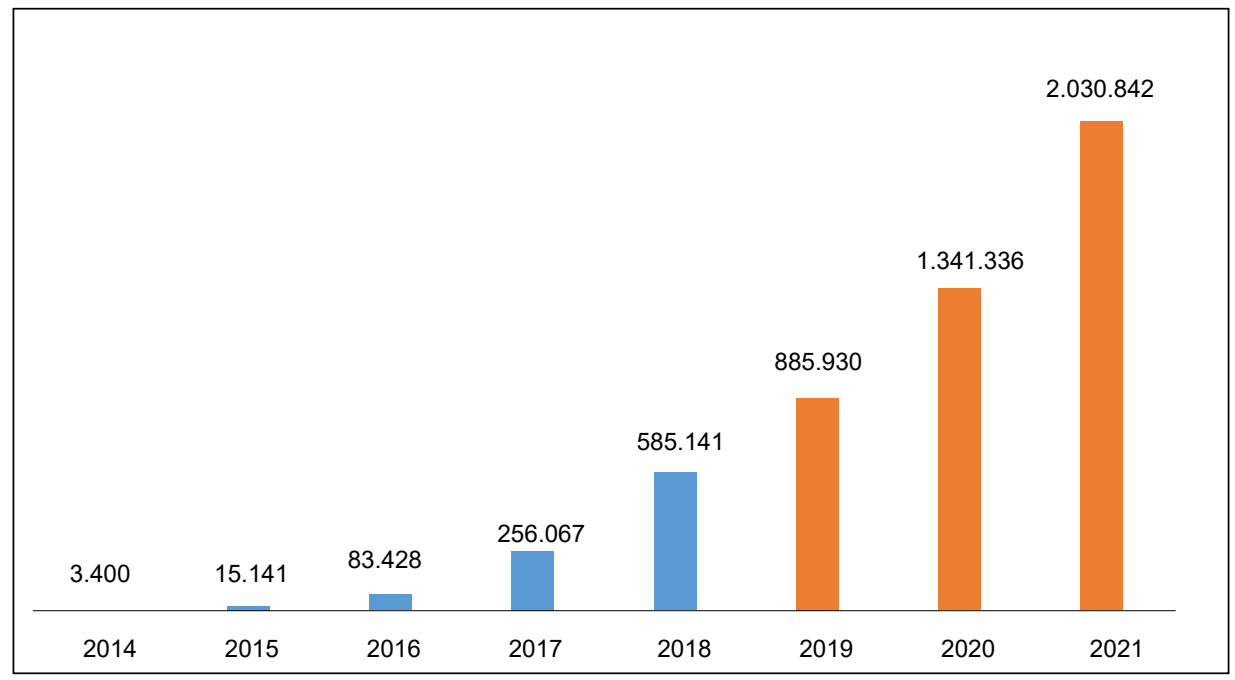

Fonte: Elaborada pelo autor utilizando dados da ANEEL (2014 a 2018).

A Figura 10 mostra a previsão de clientes de GD instalados no Brasil. Considerando as premissas de crescimento encontradas no país para os consumidores, constrói-se um cenário para os próximos três anos. As unidades GD têm previsão de fechar 2018 com 51,6 mil clientes e, em 2021, num total de 199 mil. A previsão de unidades GD instaladas de 2019 a 2021 foi feita considerando o crescimento dos últimos anos e adaptouse à desaceleração da expansão (conforme Figura 7) no modelo de previsão. A partir de 2019, foi mantida a mesma taxa de crescimento até 2021.

Figura 10: Previsão de unidades de GD, Brasil.

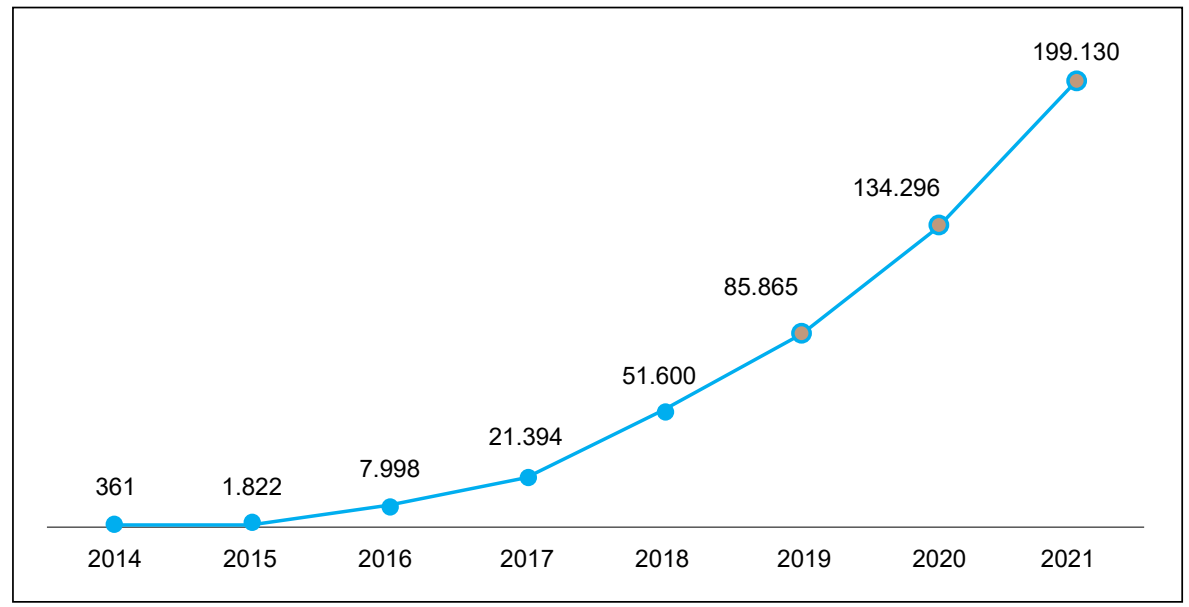

Fonte: Elaborada pelo autor utilizando dados da ANEEL (2014 a 2018). 
A Figura 11 apresenta a relação entre a potência instalada pela quantidade de clientes de GD no Brasil (kW/Cliente). Observa-se que, de 2014 a 2015, houve uma redução relação. Até 2017, a relação cresceu. Em 2018, já se nota uma queda. A previsão feita para os anos de 2019 a 2021, tanto para potência instalada quanto para clientes de GD no Brasil, faz com que a relação kW/cliente fique estável, em torno de $10 \mathrm{~kW} /$ cliente, ou seja, a previsão realizada não altera a relação kW/cliente de GD.

Figura 11: Relação kW/cliente de GD, Brasil.

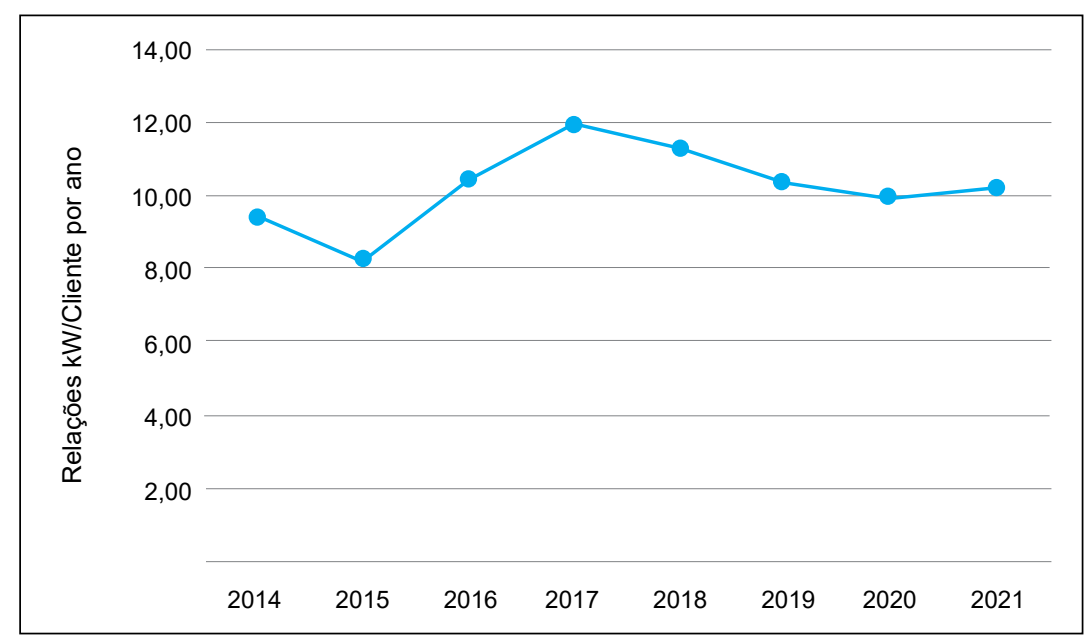

Fonte: Elaborada pelo autor utilizando dados da ANEEL (2014 a 2018).

\subsection{Dados de GD do Nordeste (estados do Ceará, Bahia, Pernambuco, Rio Grande do Norte e Piauí)}

A Figura 12 mostra a evolução da potência instalada de GD no Nordeste. Nota-se um acentuado crescimento no Ceará a partir de 2016, que segue com um avanço linear até 2017 e tem uma leve inclinação para baixo em 2018. Exclusivamente em 2018, o Ceará representa $41 \%$ da potência instalada total dos 5 estados, seguido por Pernambuco (19\%), Bahia (16\%), Rio Grande do Norte (13\%) e Piauí (11\%). Analisando a expansão do Ceará frente aos demais estados, observa-se que o segmento comercial no Ceará, desde 2016, tem apesentado uma potência instalada superior às demais federações. Essa característica contribui para a posição do Ceará na liderança da GD no Nordeste.

Figura 12: Evolução potência instalada (kW), Nordeste.

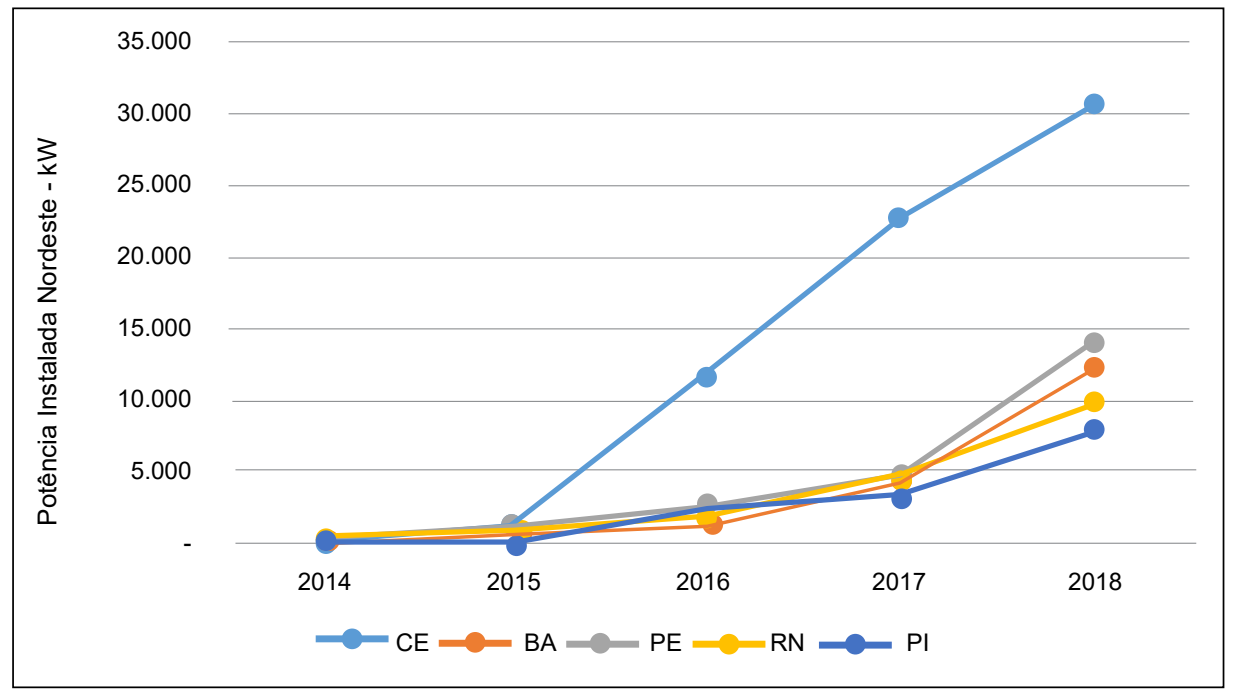

Fonte: ANEEL (2014 a 2018). 
A Figura 13 apresenta a evolução do número de clientes conectados à GD do Nordeste. Observa-se, também, um crescimento no Ceará a partir de 2016, que segue no mesmo ritmo até 2018. Exclusivamente em 2018, o Ceará representa $31 \%$ dos clientes de GD do total dos 5 estados, seguido Bahia (25\%), Pernambuco, Rio Grande do Norte (14\%) e Piauí (11\%).

Figura 13: Evolução clientes de GD, Nordeste.

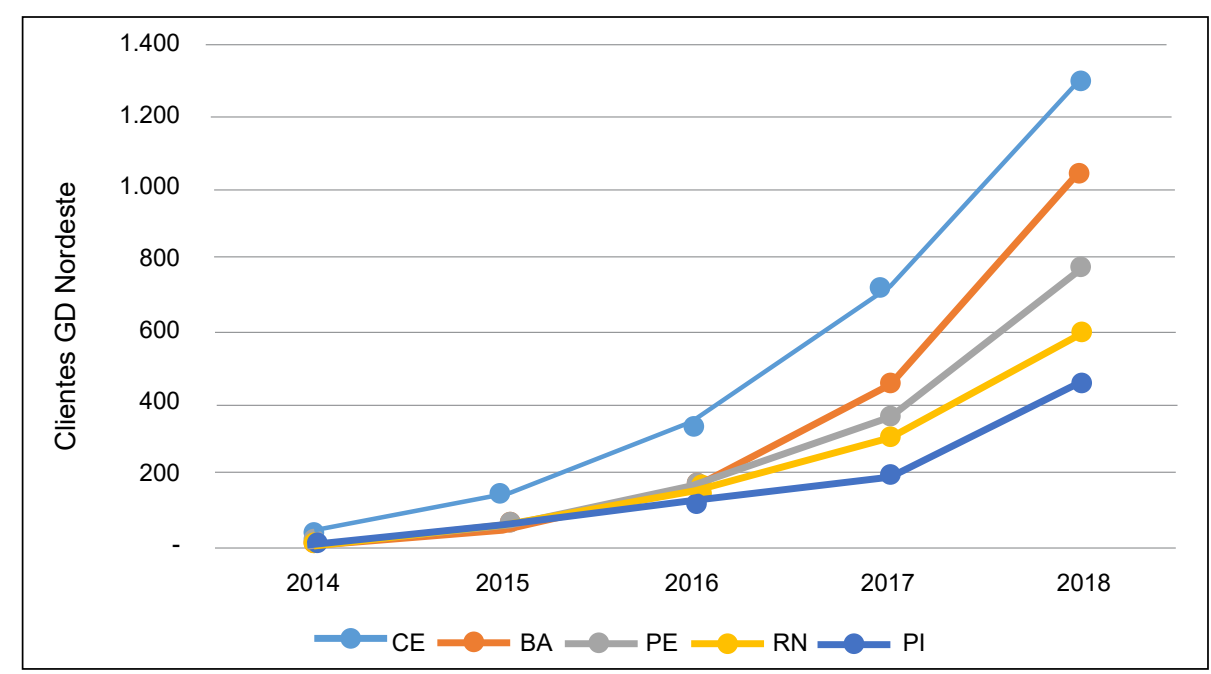

Fonte: ANEEL (2014 a 2018).

A Figura 14 detalha a participação dos estados analisados na potência de GD instalada total. Após a análise, constata-se uma redução percentual da potência instalada em Pernambuco frente ao restante do Nordeste, assim como uma expansão percentual da potência no Ceará devido ao processo mencionado anteriormente.

Figura 14: Participação dos estados analisados na potência GD instalada, Nordeste.

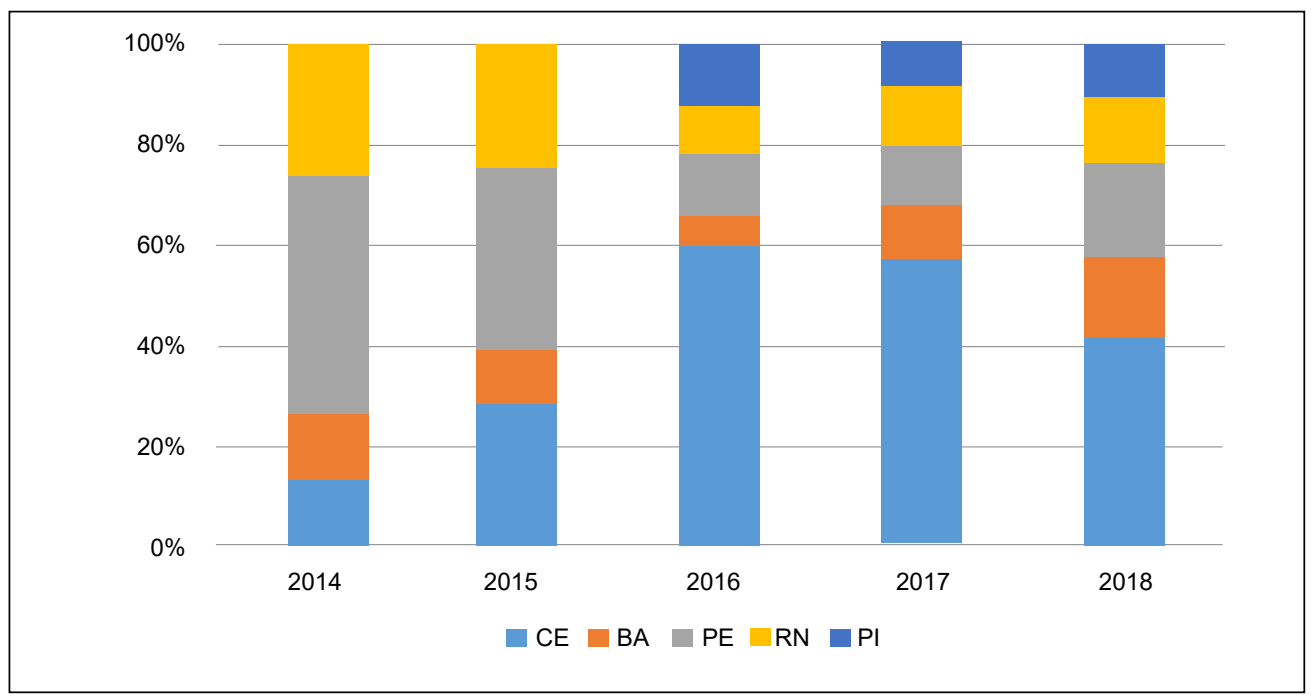

Fonte: ANEEL (2014 a 2018).

\subsection{Dados de GD do Ceará}

A Figura 15 mostra as medições do fator de capacidade (FC), medido no período de setembro de 2016 a agosto de 2017 em uma planta FV de 1,5 kWp conectada à rede instalada no Laboratório de Energias 
Alternativas da Universidade Federal do Ceará (LEA-UFC), em Fortaleza, Ceará. O desenvolvimento do FC mostra, claramente, as condições meteorológicas locais: a maioria das precipitações (cerca de $80 \%$ ou mais da precipitação) ocorre dentro da estação chuvosa (janeiro-junho), e muito pouco durante o resto do ano. Um valor médio de FC de $20 \%$ é calculado para o período mencionado (Carvalho et al., 2018).

Figura 15: Fator de capacidade, setembro de 2016 a agosto de 2017, LEA-UFC, em Fortaleza, Ceará.

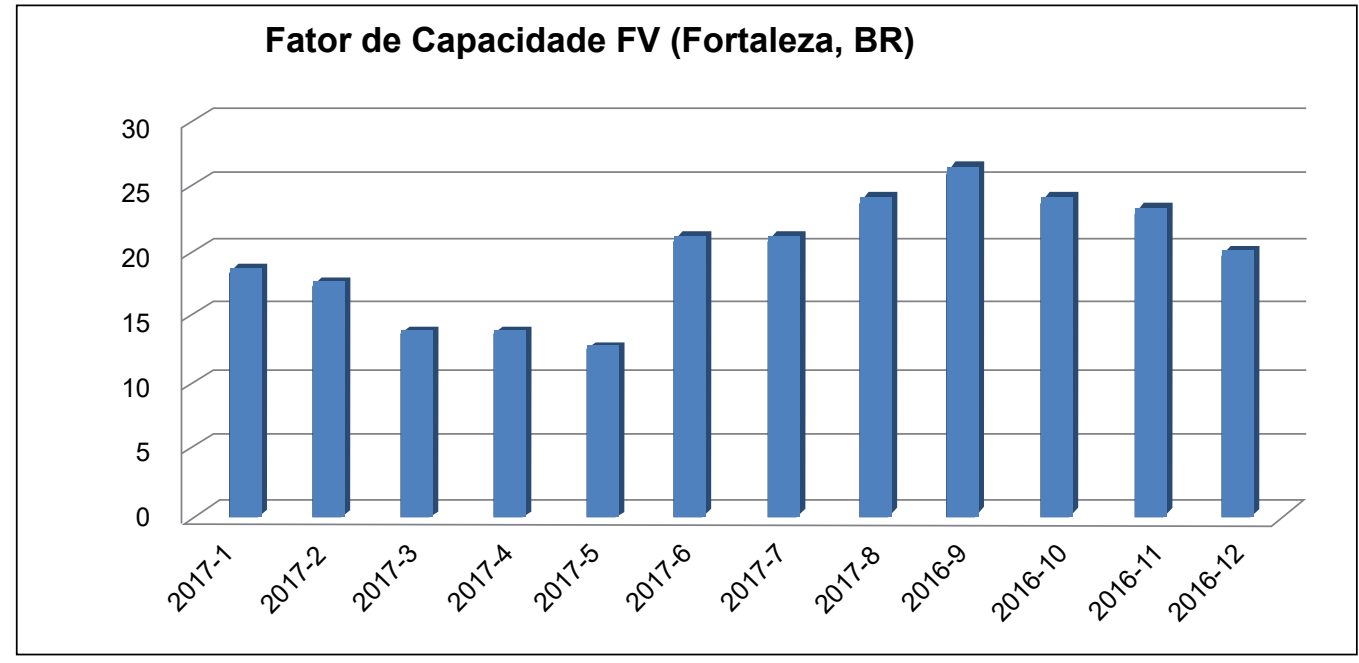

Fonte: Dados do LEA-UFC (Set/2016 a Ago/2017).

A Figura 16 mostra a taxa de crescimento anual do número de clientes GD no Ceará. Em linha com os dados do Brasil, o ano de 2015 apresenta, no estado, um avanço de 306\% frente ao ano de 2014, fruto do reflexo da aprovação do Convênio ICMS 16/2015. Nos anos seguintes, há uma desaceleração da expansão, fruto da mencionada crise econômica nacional. Em 2018, a base de clientes está $77 \%$ acima em relação ao ano de 2017. Destaca-se que estão computados os dados até outubro de 2018, já a comparação de 2017 é com o ano todo.

Figura 16: Taxa de crescimento anual do número de clientes de GD, Ceará.

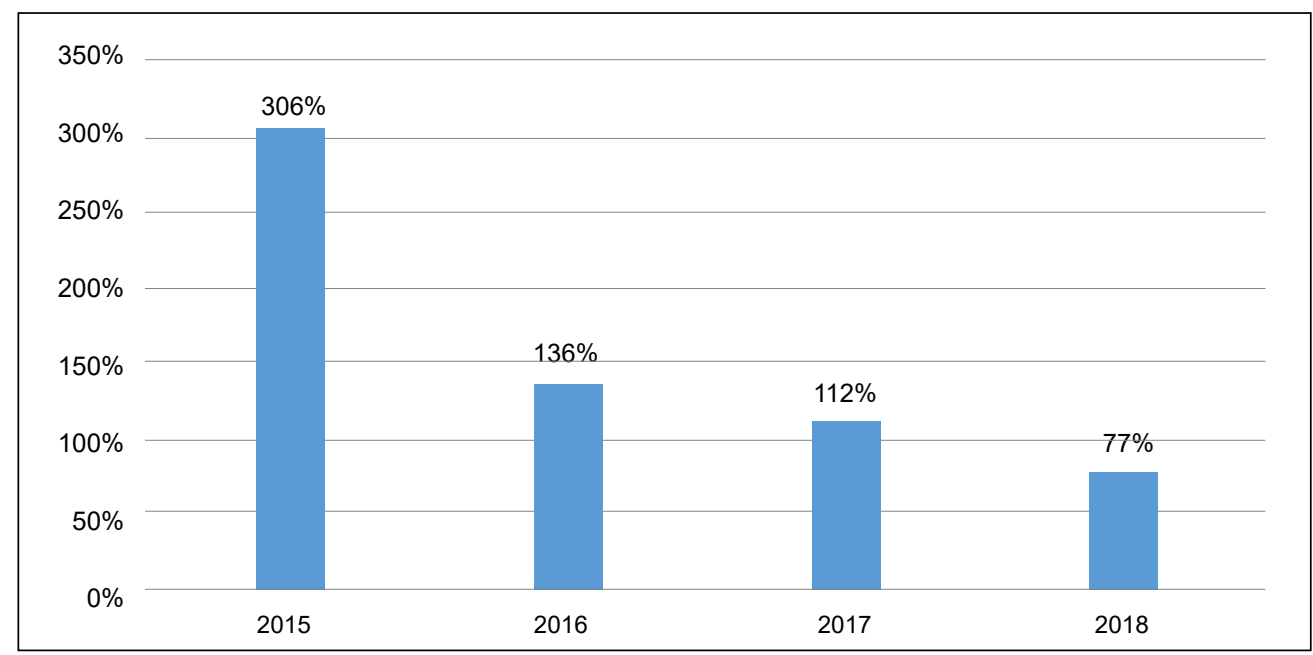

Fonte: ANEEL (2015 a 2018). 
Já a Figura 17 apresenta o crescimento anual da potência instalada de GD no Ceará, caracterizado por elevadas taxas de crescimento, principalmente nos anos de 2015 e de 2016. Nos anos seguintes, há uma desaceleração da expansão. Em 2018, a potência instalada está 36\% acima em relação ao ano de 2017.

Figura 17: Crescimento anual potência instalada de GD, Ceará.

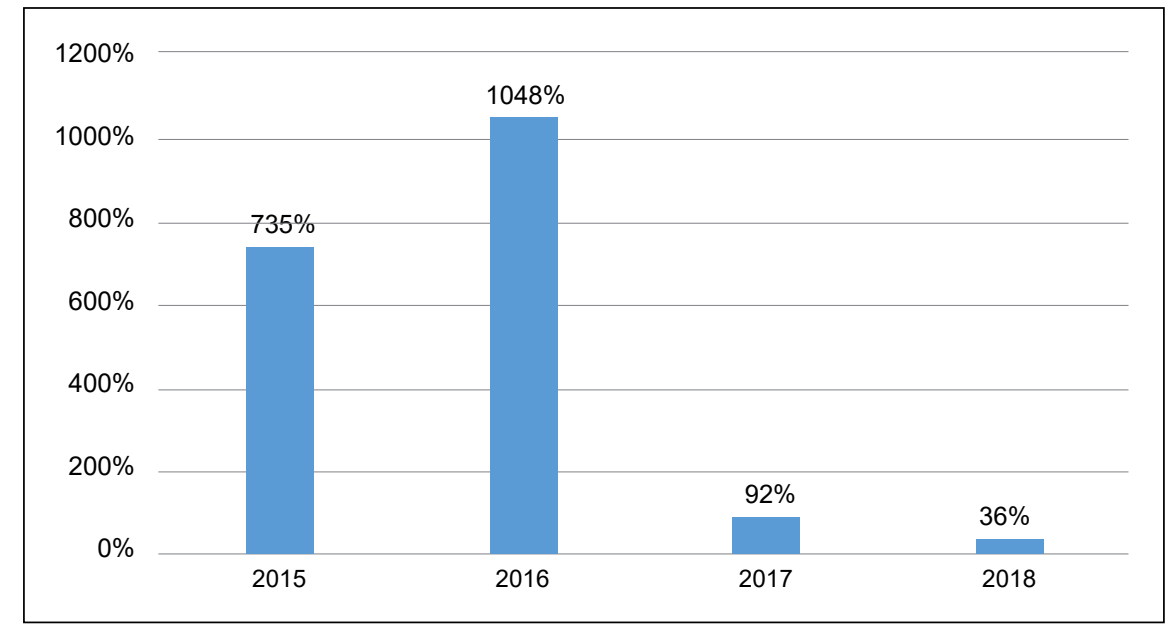

Fonte: ANEEL (2015 a 2018).

\section{Conclusão}

A introdução de legislação e incentivos por parte do governo brasileiro em GD está aumentando a participação de empresas de fontes renováveis na matriz elétrica nacional nos últimos anos, especialmente em relação aos sistemas FV. Após a implantação da GD, em 2012, as conexões de GD chegaram, em outubro/18, a 43.160 unidades, com uma potência instalada de 530,1 MW. Apesar da desaceleração causada pela crise econômica nacional, as taxas de crescimento para o setor FV ainda podem ser consideradas elevadas.

Foi constatado que o incentivo regulatório do Convênio ICMS 16/2015 foi fundamental para expansão da GD, principalmente a partir de 2015. No caso do Brasil, a potência instalada avançou neste ano, sendo $345 \%$ frente a 2014 e, no caso do Ceará, a expansão foi de 735\%. Em 2017, os avanços continuaram significativos e, em 2018, o crescimento no Brasil está em 107\% e, no Ceará, 36\%.

Os resultados obtidos recomendam a adesão ao Convênio ICMS 16 para todas as unidades federativas de Brasil.

Já em relação a linhas de financiamento, a principal instituição financeira, BNDES, em junho/18, abriu linha de crédito para pessoas físicas com taxas a partir de $4,03 \%$ ao ano. Esse incentivo pode impulsionar ainda mais a GD no Brasil.

Destaca-se, também, que a injeção de eletricidade oriunda da GD contribui para a postergação de investimentos em geração no país, uma vez que os clientes de GD assumem participação na geração. Com isso, evita-se que se construa uma central de geração para atendimento ao mercado de energia elétrica.

Espera-se que, em 2021 tenha-se 199.130 clientes de GD conectados à concessionária, com uma potência instalada de $2.031 \mathrm{MW}$. O desafio é prever os próximos passos da GD, os caminhos para onde pode seguir. Em meados de 2018, através da consulta pública 010/2018, a ANEEL colocou em discussão o tema da GD para que houvesse contribuição de toda a sociedade, com a finalidade de aperfeiçoar a Resolução n. ${ }^{\circ}$ 482/2012. Está previsto para o primeiro semestre de 2019 que esse tema entre em audiência pública e que, no segundo de semestre de 19, já exista uma resolução mais aprimorada, quando dimensionar quais serão seus impactos regulatórios. 


\section{Referências}

AGÊNCIA NACIONAL DE ENERGIA ELÉTRICA. Decreto $\mathbf{n}^{\circ} \mathbf{7 8 6 / 2 0 1 7}$, de 17 de outubro de 2017. Altera a Resolução Normativa n 482, de 17 de abril de 2012. Brasília: ANEEL, 2017.

AGÊNCIA NACIONAL DE ENERGIA ELÉTRICA. Informações de geração distribuída de 2017 no Brasil. Disponível em: <http://www.aneel.gov.br/sala-de-imprensa-exibicao/-/asset_publisher/XGPXSqdMFHrE/ content/geracao-distribuida-ultrapassa-20-mil-conexoes/656877? inheritRedirect=false\&redirect=ht tp\%3A\%2F\%2Fwww.aneel.gov.br\%2Fsala-de-imprensa-exibicao\%3Fp_p_id\%3D101_INSTANCE_ XGPXSqdMFHrE\%26p_p_lifecycle\%3D0\%26p_p_state\%3Dnormal\%26p_p_mode\%3Dview\%26p_p_col_ id\%3Dcolumn-2\%26p_p_col_count\%3D2>. Acesso em: 03 nov. 2018.

AGÊNCIA NACIONAL DE ENERGIA ELÉTRICA. Micro e minigeração distribuída, sistema de compensação de energia elétrica. Brasília: ANEEL, 2016a. (Cadernos Temáticos ANEEL). Disponível em http://goo.gl/ttCi3b. Acesso em: 02 set. 2018.

AGÊNCIA NACIONAL DE ENERGIA ELÉTRICA. Resolução Normativa n 414, de 9 de setembro de 2010. Estabelece as condições gerais de fornecimento de energia elétrica de forma atualizada e consolidada. Brasília 2010.

AGÊNCIA NACIONAL DE ENERGIA ELÉTRICA. Resolução normativa n 482/2012, de 17 de abril de 2012. Estabelece as condições gerais para o acesso de microgeração e minigeração distribuída aos sistemas de distribuição de energia elétrica, o sistema de compensação de energia elétrica. Brasília: ANEEL, 2012.

AGÊNCIA NACIONAL DE ENERGIA ELÉTRICA. Resolução normativa n 687/2015, de 24 de novembro de 2015. Altera a Resolução Normativa n 482, de 17 de abril de 2012, e os Módulos 1 e 3 dos Procedimentos de Distribuição - PRODIST. Brasília: ANEEL, 2015.

BANCO NACIONAL DE DESENVOLVIMENTO ECONÔMICO E SOCIAL. BNDES muda regra e pessoas físicas podem investir em energia solar. Rio de Janeiro, 5 jun. 2018. Disponível em: <https://www.bndes. gov.br/wps/portal/site/home/imprensa/ noticias/ conteudo/bndes-mbndesuda-regra-e-pessoas-fisicaspodem-investir-em-energia-solar>. Acesso em: 03 nov. 2018.

BORGES Neto, M. R.; CARVALHO, P. C. M. Geração de Energia Elétrica - Fundamentos. São Paulo: Érica, 2012.

BRASIL. Decreto $n^{\circ}$ 5.163/2004. Regulamenta a comercialização de energia elétrica, o processo de outorga de concessões e de autorizações de geração de energia elétrica. Brasília, 2004. Disponível em: <http://www.planalto.gov.br/ccivil_03/_Ato2004-2006/2004/Decreto/D5163.htm>. Acesso em: 03 nov. 2018.

CARVALHO, P. C. M. et al. Land requirement scenarios of PV plants in Brazil. Renewable Energy \& Power Quality Journal. n.16, abr. 2018. Disponível em: <https://doi.org/10.24084/repqj16.252>. Acesso em: 27 nov. 2018.CONCEIÇÃO, I. L. da. Raio-X da micro e minigeração distribuída no Brasil. Florianópolis: TSBE, . Disponível em: <http://tsbe.com.br/noticias/raio-x-da-micro-e-minigeracao-distribuida-no-brasil-4>. Acesso em: 23 abr. 2019.

EMPRESA DE PESQUISA ENERÉTICA. Anuário Estatístico de Energia Elétrica 2018. Rio de Janeiro: EPE, 2018. Disponível em: <http://www.epe.gov.br/pt/publicacoes-dados-abertos/publicacoes/anuarioestatistico-de-energia-eletrica>. Acesso em: 27 nov. 2018.al -

PEREIRA, R. O que é Geração Distribuída - GD. Portal Solar. Disponível em: <https://www.portalsolar. com.br/o-que-e-geracao-distribuida.html>. Acesso em: 23 abr. 2019. 
Sobre os autores

\section{Robson da Silva Dias}

Graduação em Engenharia Elétrica pela Universidade Federal do Ceará (2010). Trabalhou de (2011) a (2018) como analista de regulação da Companhia Energética do Ceará. Tem experiência na área de Engenharia Elétrica, com ênfase em Distribuição de Energia Elétrica. Também tem experiência nas áreas de comercialização de energia, regulação técnicocomercial e gestão de energia elétrica.

Recebido em: 09.12.2018

Aceito em: 28.04.2019 